\title{
Prevention of Mother-to-Child Transmission of Hepatitis B in the Urban District Health Baskuy Burkina Faso
}

\author{
Alice Nanelin Guinganée, ${ }^{1,2}$, Nicolas Meda ${ }^{3,4}$, Roger Sombié1,3, Christiane Béré/Somé1, \\ Lydie Sia' ${ }^{1}$, Rose Ido/Da1, Issa Guiraud ${ }^{5}$, Alain Bougouma ${ }^{1,3}$ \\ ${ }^{1}$ Service d'Hépatogastroentérologie, CHU-Yalgado Ouédraogo, Ouagadougou, Burkina Faso \\ ${ }^{2}$ Aix Marseille University, IRD, UMR-S912, Marseille France \\ ${ }^{3}$ Faculty of Health Sciences (UFR-SDS), University of Ouaga I Pr Joseph Ki-Zerbo, Ouagadougou, Burkina Faso \\ ${ }^{4}$ Centre MURAZ, Bobo-Dioulasso, Burkina Faso \\ ${ }^{5}$ Institute of Research on Health Sciences, Ouagadougou, Burkina Faso \\ Email: *aliceguingane@yahoo.fr
}

Received 7 May 2016; accepted 6 June 2016; published 9 June 2016

Copyright (C) 2016 by authors and Scientific Research Publishing Inc.

This work is licensed under the Creative Commons Attribution International License (CC BY). http://creativecommons.org/licenses/by/4.0/

(c) (i) Open Access

\section{Abstract}

Few studies have been conducted on the epidemiology in pregnancy in sub-Saharan Africa. This study aimed to improve the care of pregnant women infected with hepatitis B virus (VHB) and their newborns in the urban district health. Method: This study was conducted from 01/09/2014 to 01/09/2015. Study involved three types of data collection: a collection of data from health facilities involved in the project; repeated cross-sectional survey among health personnel; a prospective study of pregnant women identified positive for HBsAg and followed at the University Hospital Yalgado Ouédraogo (CHU-YO). Knowledge assessment was made among health staff and pregnant women using a knowledge score. Construction of the score came after a factorial analysis of multiple correspondences on population health workers surveyed in the first round $(N=119)$ on one hand and all pregnant women $(\mathrm{N}=266)$ on the other hand. This had identified among the 79/19 questions, those that discriminated best knowledge of paramedics and pregnant women. For pregnant women, this score was then dichotomized from the center and logistic regression was performed to determine the sociodemographic, medical and obstetric characteristics that influenced it ( $p$ value $<005)$. Results: Health staff had been surveyed twice $(N=119 / 100)$. In general, the level of knowledge was good on targeted knowledge, both before and after training. No health worker routinely offered screening for hepatitis B among pregnant women attending antenatal clinics. Altogether 266 pregnant women HBsAg-positive were referred and followed CHU-YO. Half of the patients had a score lower than 2/17. Univariate analysis showed that variables such as education level influenced significantly the level of knowledge. Women with

${ }^{*}$ Corresponding author.

How to cite this paper: Guingané, A.N., Meda, N., Sombié, R., Béré/Somé, C., Sia, L., Ido/Da, R., Guiraud, I. and Bougouma, A. (2016) Prevention of Mother-to-Child Transmission of Hepatitis B in the Urban District Health Baskuy Burkina Faso. Open Journal of Gastroenterology, 6, 175-187. http://dx.doi.org/10.4236/ojgas.2016.66023 
higher levels of education had a higher level of knowledge about the disease, compared to those of primary level $[O R=1.63 ;[1.34$ to 1.99$]$, $p$ value $<0,001]$. Newborns during the study period numbered 128 and the vaccine was made in the first 24 hours of life for $83.6 \%$ of them. Conclusion: routine screening for infection with VHB during pregnancy and improved knowledge of mothers is strongly reco- mmended in Burkina Faso.

\section{Keywords}

\section{Hepatitis B, Paramedics, Knowledge, Practices, Pregnant Women, Immunization, Newborn}

\section{Introduction}

The World Health Organization (WHO) estimates that about 2 billion people are infected with HBV worldwide and about 350 million of them suffer from chronic hepatitis B [1]. It is also estimated that about 65 million among all people chronically infected live in Africa [2] and that hepatitis B is responsible for the deaths from 500,000 to 1.2 million people each year [1]. Overall, the impact of chronic liver disease (including HBV) is very important, and liver cancer is the third most common cause of cancer deaths worldwide [3].

In endemic areas, perinatal transmission is the main mode of HIV transmission: no vaccination or prophylaxis within 24 hours of birth, 70\% to $90 \%$ of children born to positive mothers HBs antigen (HBsAg)-main marker chronic HBV infection are infected with HBV before the age of six months [1]. Studies also show that, if a young person is infected with HBV, the risk of developing chronic infection is high: it is estimated that $15 \%-25 \%$ of adults who contract chronic infection in childhood will die prematurely from liver complications, cirrhosis or liver cancer [4].

In sub-Saharan Africa, the main challenge today is the prevention of mother to child transmission of hepatitis $B$ virus in order to break the chain of transmission of this infection, which is essentially perinatal and limits the impact this infection morbidity and premature mortality in adulthood.

Problematic: Burkina Faso, despite some progress in particular in the treatment of hepatitis B, it is found that pregnant women and their babies rarely have a proper prevention and management burden. First, pregnant women are rarely screened for hepatitis B during their pregnancy, mainly because of insufficient knowledge of health professionals involved in the monitoring of pregnant women (auxiliary midwives, midwives/maieuticians) on prevention and treatment of hepatitis B.

Second, the reference current system for pregnant women with positive serology for HBsAg is complex: it is, at first, auxiliary midwives to midwives, then to midwives to Gynecologists; and the last to Gynecologists to hepato-gastroenterologists. This long therapeutic route leads to the fact that many women already physically and economically exhaust by pregnancy and the many expenses that these entails do not seek to end the hepatogastroenterologists. However only them (hepato-gastroenterologists) in the current context of the country are able to provide adequate care to both mother and child whatever the clinical picture. Finally, the immunization schedule currently used in the country is not suitable. WHO recommends indeed vaccinating infants at birth, preferably within the first 24 hours of life but in Burkina Faso, vaccination against hepatitis B is carried out in the eighth week of life, exposing infants to a risk of contamination during their first two months of life.

The absence of national policy and program against hepatitis severely limits the activities of health professionals which remain devoid of global thinking on how to organize care in the health system as a whole. Faced with this situation, an initiative is taken by hepato-gastroenterologists to set up a device to urban health district Baskuy Burkina Faso and should help solve the problem.

\section{Methodology}

\subsection{Type and Date of Study}

This study was conducted from 01/09/2014 to 01/09/2015. The study combines three types of data collection:

- A repeated cross-sectional study among health facilities involved in the project. This allow, to identify during the study period all pregnant women attending antenatal and benefitting from HBV screening; the different 
results of screening tests; the number of women referred to CHU-YO; the number of newborns vaccinated at birth.

- A repeated cross-sectional survey among health personnel working in the health facilities involved in the project (two months spaced studies);

- A prospective study identified positive pregnant women for HBsAg and followed to their infection CHU-YO. This study was conducted as part of routine care of patients after informed consent.

\subsection{Ethical Approval}

Prior informed consent from the patients was required. The analysis was conducted on anonymized data, collected as part of routine patient care. No additional investigations were performed.

\subsection{Statistical Analyses}

\subsubsection{Descriptive Analyzes of the Population of Health Workers}

Regarding health personnel, we were able to describe their socio-demographic characteristics, the professional context and the workload of health workers and assess their level of knowledge about hepatitis B before the implementation of the model and two months after.

\subsubsection{Assessing the Impact of the System on the Level of Knowledge of Health Professionals}

The questionnaire to the health workers included 79 questions directly related to the knowledge of professionals on infection, habits and practices vis-à-vis the prevention of infection which they could answer by checking "yes", "no" or "do not know". Every correct answer to a question was rated "1", each wrong answer was rated " 0 ". For the purpose of statistical analysis, no response has been considered asan incorrect answer rated as " 0 ", except if the respondent had given up the questionnaire (in this case the answer was missing data). Failure to answer the questionnaire was defined as a non-answer to all the questions in the part on knowledge.

\subsubsection{Construction of Knowledge Scores of Health Workers and Comparison before and after Training}

Health staff have beensurveyed twice in a two-month interval ( $N=119$ first round and second round $N=100)$ to assess the impact of our intervention (training) on their knowledge. The construction of the score was performed on the population of health workers surveyed before the training which represents the initial situation ("baseline" with $\mathrm{N}=119$ ).

A factorial multiple correspondence analysis (ACM) was used to select among the 79 questions, those which best discriminated the knowledge of paramedics (variables having a sufficiently large discrimination rate, with in practice a measure of discrimination over 0.10 ). And 32 variables were selected fixing the total score to 32/32. A Cronbach's alpha was calculated (selected threshold to 0.9) to check the internal consistency of the items included in the knowledge scored after the factorial analysis of multiple correspondences. The 32 variables used had good Cronbach's alpha equals to 0.92 .

The distribution of the percentage of health workers who correctly answered the knowledge questions was then described in the two study populations $(\mathrm{n}=71)$ found in both the first $(\mathrm{N}=119)$ and second round $(\mathrm{N}=$ 100 ), then according to socio-professional categories.

The knowledge score was described in a subgroup of the study population found in both surveys $(n=71)$ for comparison. For the comparison we also decided to calculate the knowledge scores before and after training for 71 health workers, on the basis of 32 questions resulting from the ACM of the first round.

A sensitivity analysis was performed to confirm the validity of the knowledge score in the 2nd round of population (given that the score was constructed using data from the first round for the purpose of comparison). For this, we conducted an ACM based on the answers of the 2nd round and then tested the correlation between the two scores. We found a strong positive correlation to $0.93(0.89$; 0.95$)$. This allows us to apply for the two surveys, the frame score on 32 variables based on the assurance of the robustness of our results. The comparison of the two medians of knowledge score was made by an average comparison test (Wilcoxon test).

\subsubsection{Construction of Knowledge Scores of Infected Pregnant Women}

The questionnaire sent to pregnant women included 19 questions relating directly to their knowledge. The same 
methodology as described above for health workers has been used in pregnant women. Of the 19 questions, those that discriminated best women's knowledge (variables that have significant discrimination rate with in practice a measure of greater discrimination than 0.20 ) were retained (17 variables) fixing the total score $17 / 17$.

\subsubsection{Analysis of Factors Associated with Knowledge Score of Pregnant Women}

Analysis of factors associated with knowledge score of pregnant women after verification by the Shapiro test ( $\mathrm{p}$-value $=0.0002748)$ for the distribution of knowledge score, we found that it did not follow a normal distribution, which is why we chose to make a logistic regression dichotomizing the variable score from the median. Thus the score less than or equal to the median were considered "bad" and one above the median considered "good". Then uni and multivariate regressions were then performed to identify factors (sociodemographic, medical and obstetric) associated with a good score of knowledge; $\mathrm{p}<0,05$ was selected.

All variables were included in the initial model and stepwise regression in both directions "both" was conducted resulting in the final model was the one with the smallest AIC (Akaike Information Criterion). All analyzes were worn only on observations without missing data. The distribution of the score in pregnant women do not follow a normal distribution, we compared the median according to the educational level by a nonparametric test, the kruskal. test.

\section{Results}

The survey before the training showed that female health workers $(n=160,89.07 \%)$, married $(n=93,78.15 \%)$ and aged between 41-50 years $(n=54,45.37 \%)$ predominated in the population that participated $(n=119)$ in the study. A majority ( $n=108,90.7 \%)$ claimed to have previously received training on the subject of viral hepatitis B. Concerning their own screening, only 42 health workers (35.3\%) had already been tested and 104 (87.28\%) were immunized. The average number of doses was three (3).

No health worker routinely offered hepatitis B screening to pregnant women attending antenatal clinics. The reasons given for the failure to implement the screening were varied, including lack of awareness of the high prevalence $(n=29,24.36 \%)$, ignorance of the need for screening $(n=26,21.84 \%)$, absence of laboratory $(n=$ $32,26.89 \%)$, unavailability of laboratory test $(n=13,10.92 \%)$, rupture of laboratory reagents $(n=4,3.36 \%)$ and the low purchase power of women $(n=31,26.05 \%)$. Only 45 health workers $(38 \%)$ referring patients to hépato-gastro-enterologist.

In general, the level of knowledge was good both before and after training. About 94\% ( $\mathrm{n}=67) \mathrm{knew}$ the causal agent of the infection, as well as the affected organ. The modes of transmission were generally well known 39 to 67 health workershad the correct answer (54.9\% to 94.4\%). But only 26\% knew that breastfeeding was still possible for children born to HBsAg-positive mothers. A majority of workers (54.9\%) incorrectly stated that saliva was a means of contamination.

Regarding diagnostic methods, all the rates of correct answers were above $80 \%$. The lower rate concerned the molecules used in the treatment of hepatitis B. The percentages of correct answers (the 1st and 2nd round) in the population surveyed in both rounds $(n=71)$ according to the professional status of the practitioner.

\subsection{Impact of Training on the Knowledge Scores ( $n=71)$}

Calculating the average scores showed that the median score before training was 27 with its interquartile range of 19 to 30 against 29 after training with its interquartile range of 26 to 31 . The Wilcoxon test results showed that there is a significant difference between the two scores ( $p$-value $=0.005059)$.

We can therefore say that the training of health workers has improved their level of knowledge. Figure 1 gives the distribution of knowledge score before and after training of health workers.

\subsection{Activities in the Nine District Health Centers}

The field survey in the 9 district health centers revealed that there was no systematic screening for hepatitis B among pregnant women before our interventions (training). After the training received by health workers about hepatitis B, all HBs Ag positive women (266) were referred to CHU-YO in the range of 12 months.

\subsection{Description of the Characteristics of Infected Pregnant Women and Their Newborns}

Of the 266 pregnant women HBsAg-positive, the most numerous were those aged between 23 and 29 years (n = 


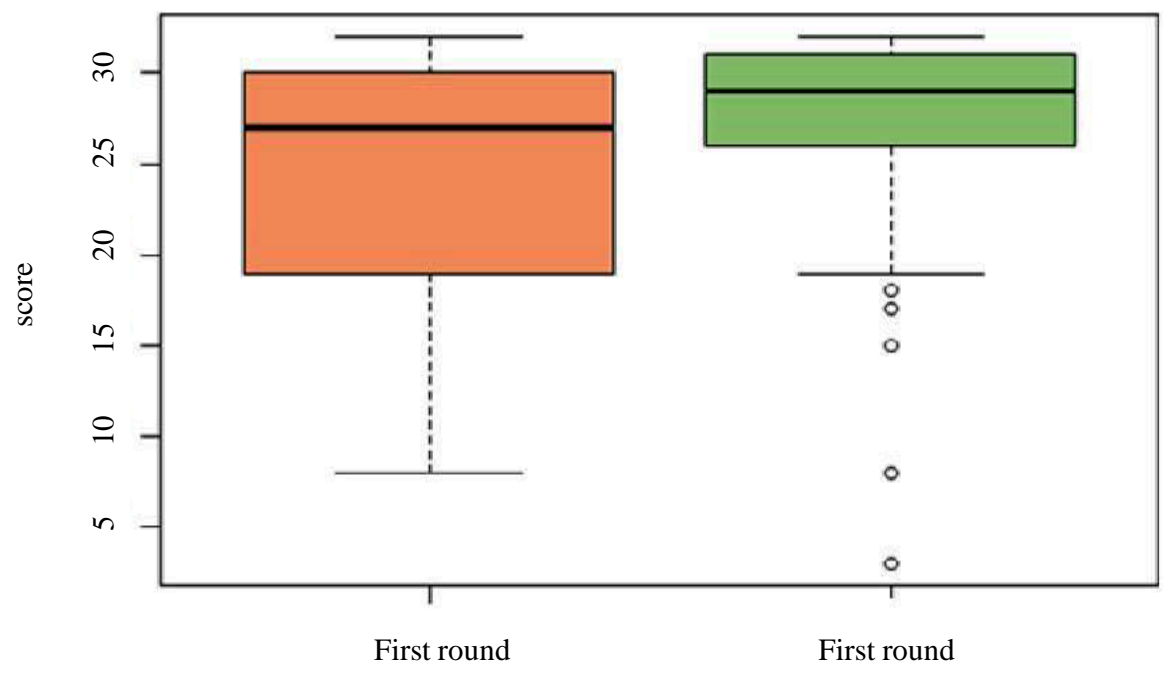

Figure 1. Distribtion of knowledge score before and after training of health workers.

$115,43.23 \%)$ in the second trimester of pregnancy $(n=150,56.39 \%)$ and multiparous $(n=145,54.5 \%)$. The infection risk factor most found was the excision in $59.4 \%$ of cases $(n=158)$ while, less frequent concerned the history of previous transfusion with $4.89 \%$ of cases $(n=13)$. A minority of women had been vaccinated before prenatal care $(n=6,2.26 \%)$.

The sharing of information with spouse had been possible in $84.21 \%$ of cases $(\mathrm{n}=224)$ and about 119 spouses who made the screening, 15 (12.6\%) were positive. About entourage, $64.3 \%$ of women $(n=171)$ did not want to disclose information about their status. In the vast majority of cases $(n=190,71.6 \%)$ the expenses were borne by the spouse. More than half of women $(n=164,61.8 \%)$ said they had never heard of this infection before the screening prenatally. For those who had heard the most used channel was the media $(n=44,43.13 \%)$ and chats ( $\mathrm{n}=40,39.21 \%)$.

Newborns during the study period numbered 128 (48.12\%) with a male predominance. Caesarean section was performed in 35 cases (13.28\%). Some complications were found such as miscarriage and stillborn in $3.91 \%$ and $1.56 \%$ in prematurity. The characteristics of pregnant women and their newborns, are shown in (Table 1).

\subsection{Knowledge Score of Infected Pregnant Women}

The total score was 17/17 (after ACM) for those who answered all the questions. The level of knowledge was low because half of the patients had a knowledge score lower than 2/17. The average score was 6.8 with a range of 0 to 17. The median score was 2 with its interquartile range ( 0 to 15$)$. The score varied very significantly depending on the level of education of women. Comparing the average scores by kruskal.test with a p-value = 3.441e-15 allows us to conclude that the knowledge score varies significantly with the level of education of pregnant women.

More than half of women $(n=150,56.5 \%)$ knew that the infection was transmitted from mother to child and $128(48.1 \%)$ of them believed that hepatitis B is a deadly disease. Table 2 illustrates the percentage of correct answers according to the level of education of women.

\subsection{Influence of Variables on the Knowledge Score of Infected Pregnant Women}

Univariate analysis of variables such as age $[\mathrm{OR}=\mathbf{1 . 0 6}, \mathrm{p}$ value $=\mathbf{0 . 0 0 8}$ ], occupation [for example, housewives compared to health workers had a lower level $(\mathrm{OR}=0.52$, $\mathrm{p}$ value $=\mathbf{0 . 0 0 2})$ ], education level [for example, women with higher levels of education had a higher level of knowledge about the disease, compared to those of primary level $(\mathrm{OR}=1.63$, $\mathrm{p}$ value $<0,001)$, having already completed a screening of the virus hepatitis $C$ [OR $=\mathbf{1 . 5 1}, \mathbf{p}$ value $=\mathbf{0 . 0 0 1}]$ significantly influenced by the level of knowledge. While having been vaccinated against hepatitis $B$ [OR $=1.38, p$ value $=\mathbf{0 . 1 5 6}]$ and tested for HIV $[O R=1.14, p$ value $=0.136]$, the high number of pregnancy $[O R=0.99$, $p$ value $=0.474]$ and the existence of family history of hepatitis $B$ infection $[\mathbf{O R}=\mathbf{1 . 1 4}$, $\mathbf{p}$ value $=\mathbf{0 . 1 4 2}]$ did not influence this knowledge score. 
Table 1. Characteristics of pregnant women $(n=266)$ and their neonates $(n=104)$.

Total (\%)

Socio-demographic characteristics
Age (years)

$16-22$

$23-29$

$30-36$

$37-43$

\section{Number of pregnancy}

Primipare (1)

Multiparous (2 - 4)

Multipare large (>4)

Gestational age

First trimester

Second trimester

Third trimester
Blood transfusion

Surgical intervention

Endoscopy

Dental care

Stitches

Complications or not

Prematurity

Miscarriage/Abortion

No complications

Sex

Female

Male

\section{Birth weight}

$<2500 \mathrm{~g}$

$2500-3000 \mathrm{~g}$

$>3000 \mathrm{~g}$
54 (20.30)

115 (43.23)

75 (27.82)

$22(8.27)$
98 (36.8)

$145(54.5)$

$23(8.7)$

33 (12.41)

150 (56.39)

83 (31.20)

\section{Occupation \\ Health worker \\ Cashier \\ Dressing table \\ Saleswoman \\ Communicator \\ Finance/economy \\ Seamstress \\ Pupil/student \\ Student officer \\ Housewife \\ Schoolmistress \\ Secretary \\ Other}

Marital status

Single

Free Union

Fiancee

Married

Level of education

No education

Primary

Secondary cycle 1

Secondary cycle 2

$$
\text { Superior }
$$

Franco-Arabic School

Risk factors: medical and surgical history

$$
\begin{gathered}
13(4.89) \\
23(8.65) \\
16(6.02) \\
63(23.68) \\
101(37.97)
\end{gathered}
$$

\section{Newborns}

5 (3.91)

121 (94.53)

62 (48.44)

66 (51.56)

11 (8.59)

62 (48.44)

55 (42.97)

\section{Delivery route}

Vaginal birth

Caesarean

\section{Vaccine at birth}

Yes

No
Total (\%)

5 (1.88)

5 (1.88)

8 (3.01)

37 (13.91)

2 (0.75)

5 (1.88)

8 (3.01)

32 (12.03)

7 (2.63)

121 (45.49)

2 (0.75)

9 (3.38)

24 (9.02)

10 (3.76)

52 (19.55)

128 (48.12)

75 (28.2)

75 (28.2)

53 (19.92)

78 (29.32)

25 (9.40)

30 (11.28)

5 (1.88)

94 (35.34)

57 (21.43)

158 (59.40)

75 (28.2)
111 (86.72)

17 (13.28)
110 (85.94)

18 (14.06) 
Table 2. Percentage correct answers to knowledge questions by level of education of pregnant women.

\begin{tabular}{|c|c|c|c|c|c|c|c|c|}
\hline \multirow{3}{*}{ Knowledge questions } & \multicolumn{8}{|c|}{ Level of education } \\
\hline & \multirow[b]{2}{*}{ Primary } & \multicolumn{2}{|c|}{ Secondary } & \multirow[b]{2}{*}{ Superior } & \multirow{2}{*}{$\begin{array}{l}\text { Franco-Arabic } \\
\text { school }\end{array}$} & \multirow[b]{2}{*}{ Illiterate } & \multirow[b]{2}{*}{ Total } & \multirow[b]{2}{*}{ p-value } \\
\hline & & $\begin{array}{l}\text { First } \\
\text { cycle }\end{array}$ & $\begin{array}{l}\text { Second } \\
\text { cycle }\end{array}$ & & & & & \\
\hline \multicolumn{9}{|l|}{ Infection Risk Factors } \\
\hline Unprotected sex with a person & 24.5 & 42.1 & 72.0 & 73.3 & 0.0 & 11.0 & 35.5 & $0.000^{*}$ \\
\hline Use of contaminatedneedles & 30.2 & 42.1 & 80.0 & 73.3 & 40.0 & 16.4 & 39.7 & $0.000^{*}$ \\
\hline $\begin{array}{l}\text { Contact (eyes, wounds) with the blood of a } \\
\text { person who has hepatitis B }\end{array}$ & 30.2 & 30.3 & 56.0 & 43.3 & 0.0 & 13.7 & 29.0 & $0.000^{*}$ \\
\hline $\begin{array}{l}\text { From infected mother to her child during } \\
\text { pregnancy }\end{array}$ & 54.7 & 55.3 & 88.0 & 93.3 & 40.0 & 34.2 & 56.5 & $0.000^{*}$ \\
\hline $\begin{array}{l}\text { A blood transfusion with contaminated } \\
\text { blood }\end{array}$ & 37.7 & 42.1 & 84.0 & 83.3 & 20.0 & 19.2 & 43.1 & $0.000^{*}$ \\
\hline $\begin{array}{l}\text { Use of drugs intravenously with dirty } \\
\text { needles }\end{array}$ & 32.1 & 42.1 & 76.0 & 76.7 & 20.0 & 12.3 & 38.5 & $0.000^{*}$ \\
\hline Excision with used equipment & 35.8 & 42.1 & 80.0 & 76.7 & 20.0 & 16.4 & 40.8 & $0.000^{*}$ \\
\hline $\begin{array}{l}\text { Sharing of blades/razors with an infected } \\
\text { person }\end{array}$ & 34.0 & 47.4 & 76.0 & 80.0 & 20.0 & 19.2 & 42.7 & $0.000^{*}$ \\
\hline $\begin{array}{l}\text { Toothbrushes sharing especially in the } \\
\text { presence of minor bleeding }\end{array}$ & 32.1 & 43.4 & 68.0 & 76.7 & 20.0 & 16.4 & 39.3 & $0.000^{*}$ \\
\hline $\begin{array}{l}\text { Practice of ritual scarification or therapeutic } \\
\text { with the same blade for several people }\end{array}$ & 37.7 & 43.4 & 80.0 & 80.0 & 20.0 & 17.8 & 42.4 & $0.000^{*}$ \\
\hline $\begin{array}{l}\text { Manicure/pedicure with the same } \\
\text { non-disinfected equipment }\end{array}$ & 34.0 & 38.2 & 76.0 & 80.0 & 20.0 & 16.4 & 39.3 & $0.000^{*}$ \\
\hline \multicolumn{9}{|l|}{ Prevention methods } \\
\hline Vaccination & 28.3 & 36.8 & 68.0 & 80.0 & 0.0 & 8.2 & 34.4 & $0.000^{*}$ \\
\hline Safe sex & 30.2 & 31.6 & 80.0 & 80.0 & 0.0 & 16.4 & 36.6 & $0.000^{*}$ \\
\hline Screening blood donors & 30.2 & 30.3 & 80.0 & 80.0 & 0.0 & 13.7 & 35.5 & $0.000^{*}$ \\
\hline Use of disposable equipment & 30.2 & 39.5 & 76.0 & 76.7 & 0.0 & 16.4 & 38.2 & $0.000^{*}$ \\
\hline \multicolumn{9}{|l|}{ Treatment } \\
\hline Is there any treatment? & 49.1 & 52.6 & 60.0 & 60.0 & 20.0 & 23.3 & 44.7 & $0.000^{*}$ \\
\hline \multicolumn{9}{|l|}{ Mortality } \\
\hline Is the hepatitis $\mathrm{B}$ a deadly disease? & 50.9 & 50.0 & 76.0 & 76.7 & 20.0 & 24.7 & 48.1 & $0.000^{*}$ \\
\hline
\end{tabular}

In multivariate analysis those who had heard of this infection in the past had the knowledge score statistically higher [OR $=3.07$; $[1.50$ to 6.38$]$, $\mathrm{p}$ value $=0.002]$; as well as students of senior secondary $[\mathrm{OR}=4.87$; [1.22 to 24.85], p value $=0.034$.

\subsection{Impact of Maternal Education on Immunization of Infants at Birth}

Newborns during the study period numbered 128 and the vaccine was made in the first 24 hours of life for 107 of them (83.6\%).

\section{Discussion}

Health workers share the same risk factors for HBV infection than the general population, but their most frequent contact with blood and blood products increases their risk of infection [5]. Each year, 3 million health workers worldwide are accidentally exposed to blood-borne pathogens, leading 66,000 HBV infections [6]. A better understanding of their knowledge and practices on the risk of infection with hepatitis B would help to better guide the development of appropriate prevention strategies for themselves and the general population.

Burkina Faso, with a prevalence estimated at $14.47 \%$ among the general population (Issoufou Tao et al. in May 2014) [4] is a highly endemic area of hepatitis B. The lack of national policy and program to fight against hepatitis severely limits the activities of health professionals which remain very fragmented and dependent on their own will. They are limited to large cities that benefit from specialists, and lack any global reflection on 
how to organize the management in the health care system as a whole. Faced with this situation the initiative was taken by hepato-gastroenterologists to implement with the paramedics a measure aimed at improving the prevention and management of hepatitis B infection in a context of shortage of qualified personnel: the urban health district of Baskuy in Burkina Faso.

Our exploratory study revealed that hepatitis B routine screening was not performed among pregnant women seen at antenatal clinics in the facilities involved in the study. The screening of asymptomatic people is nevertheless an important tool, especially for a generally asymptomatic infection, which is transmitted during pregnancy such as chronic HBV infection. A key objective of our study was to establish the systematic screening of hepatitis B prenatally, to bring health staff to apply good practices in accordance with WHO recommendations [5]. The issue of the lack of hepatitis B screening for pregnant women attending antenatal clinics has also been raised in other studies in Africa. Assi C. et al. in Ivory Coast in a prospective study conducted in Abidjan in ten randomly chosen health centers from the list of the city's health centers found that screening for HBsAg was performed in only $4.3 \%$ of cases $(n=20)$ of prenatal consultations. Almost all patients $(98.7 \%)$ were not screened because the health worker had not ordered the test [6].

Health workers' knowledge of HBV has been repeatedly described as disappointing by various studies evaluating the knowledge, attitudes and professional risk of contracting hepatitis [7]-[11]. This study allowed us to note that overall the level of knowledge among health workers is good on targeted knowledge. The modes of contamination were well known globally by health workers. Pietra addressing different topics in Burkina Faso found in 2008 in a study on the health personnel of the health district of Nanoro some gaps about the importance of vaccination against $\mathrm{HBV}$ infection in primary prevention in case of accidental exposure to blood, as well as about the possibilities of medical management of chronic hepatitis available in Burkina Faso [11].

Moreover, lower knowledge scores than ours were found. Jonathan Chao et al, in a cross-sectional study (2010) in China on the knowledge and practices of health workers about hepatitis B and liver cancer, showed that $34 \%$ of health workers were unaware that contaminated blood, dirty needles, unprotected sex with an infected person and being born to infected mothers are all HBV transmission modes. In addition, 30\% of people were not aware that vaccination against hepatitis B was one of the best ways to prevent the transmission of HBV. Of a total knowledge score of 16, the average score of knowledge was 13 (4 - 16). The factors associated with the change in the score they found were, among others, the place of employment (rural/urban), low level of education as well as employment status [12].

If infection with hepatitis B can be effectively prevented by proper administration of the vaccine against HBV at birth of newborns, a good level of knowledge of the disease among health staff seems essential for ensure good management of people because it is an important source of information for the population [11].

Several international studies have shown, however, that the reduction of perinatal mortality and maternal morbidity depends on the acquisition, by health professionals, of skills enabling good management and monitoring of pregnancy as well as childbirth and care of newborns, including aspects related to the prevention of vertical transmission of hepatitis B. These skills can be acquired not only through training but also through practice [3]. In our study we were able to increase (significantly) through training the level of knowledge of health workers by an overall average score that rose from 27 to 29 in the hope that this will positively impact the support to pregnant women infected with the virus of hepatitis B.

Although health personnel plays a fundamental role in the fight against hepatitis B and constitutes one of the groups at high risk of contact with the hepatitis B virus who can be in turn a source of HBV infection for patients [10], very few actions affecting them are undertaken in Burkina Faso. In recent years, the Ministry of Health of Burkina Faso has adopted strategies aimed at reducing the transmission of HBV and HCV, such as the strengthening of infection control in health facilities by vaccinating health care workers against hepatitis B and blood safety measures. However, the anti-HBV vaccination is unfortunately not used in a systematic manner for the protection of health personnel in primary prevention or post-exposure prophylaxis [11]. In our study we found that vaccinations were not always made in the best conditions; there was either a lack of prior testing of vaccinated health workers or incompleteness of the doses received by the latter.

\subsection{Prevalence among Pregnant Women}

The prevalence was estimated at $11.4 \%$ in a cross-sectional study conducted in 2009 by L. Sangare et al. from 303 pregnant women admitted for childbirth at Yalgado-CHU Ouédraogo of Ouagadougou [13]. Other authors 
in Burkina Faso such as E. Collenberg, B. Dao, Simporé J. (2004 and 2006) found themselves different prevalence among pregnant women with respectively $12.9 \%, 10.7 \%$, 9.8\% and 9.3\% [14]-[17].

\subsection{Infection Transmission Modes in Burkina Faso}

According Sangaré L. et al. antenatal transmission of HBV is important among women HBsAg-positive (37.1\% of children born in $35 \mathrm{HBsAg-positive} \mathrm{mothers} \mathrm{were} \mathrm{infected);} \mathrm{this} \mathrm{rate} \mathrm{was} \mathrm{higher} \mathrm{than} \mathrm{the} \mathrm{12 \%} \mathrm{reported} \mathrm{by}$ Ilboudo et al, in Ouagadougou [18]. Despite the high endemicity of infection in the country, local data are insufficient and additional studies are needed to estimate perinatal and horizontal transmission rates.

HBV is transmitted from infected mother to her child, in three ways: in utero, during birth and after birth. [13] Intrauterine virus transmission is defined by the detection of HBsAg or HBV DNA in venous blood of the child 24 hours after birth and before the administration of vaccine against HBV [19] [20].

The modes of transmission of hepatitis B vary by region due to differences in risk factors that are observed: in South-East Asia, where prevalence of HBeAg (HBeAg) among pregnant women is very high, the mother to her child transmission is mostly vertical, while in sub-Saharan Africa, $\mathrm{HBeAg}$ is less prevalent among pregnant women and the infection occurs rather by horizontal way, during and after [21] birth. Several studies suggest the mode of horizontal contamination as having a significant part in the persistence of the infection in the world [22]-[26].

\subsection{Consequences of Early Infection}

Studies show that if a young person is infected with HBV, the risk of developing chronic infection is high: it is estimated that $15 \%$ - $25 \%$ of adults who contract an infection during childhood will die prematurely liver complication, cirrhosis or liver cancer [27] [28]. Thus, a key factor in reducing the burden of disease due to HBV is to target prevention strategies for mother and child.

\subsection{Knowledge of Infection Levels among Pregnant Women}

Hong Kong is one of the first cities that introduced immunoprophylaxis newborns in 1983, with the immunoglobulin and the vaccine given to the offspring of mothers who test positive during screening for HBV infection, and this was followed by universal vaccination of all newborns in 1988 [29].

This program resulted in a decrease in HBV carrier rate in children from $10 \%$ to less than $1 \%$ and a reduction in mortality from fulminant hepatitis and hepatocellular carcinoma [30] [31]. If a decreasing prevalence of HBV infection was also expected in the general population, it remained unchanged at about $10 \%$ in recent studies. The authors hypothesized that emitted one explanation was insufficient knowledge about the HBV infection, especially as regards the prevention of horizontal transmission in the population of women of childbearing age [32].

This is the first study to our knowledge to assess in the context of Burkina Faso knowledge of pregnant women on hepatitis B. It allowed us to see that their knowledge was low. These are actually affected in the implementation of preventive measures of mother to child transmission of hepatitis B.

In multivariate analysis those already heard of this condition in the past had a score statistically higher knowledge [OR $=3.07$; [1.50 to 6.38], $\mathrm{p}$ value $=0.002$ ]; same for students in upper secondary [OR $=4.87$; $[1.22$ - 24.85], $\mathrm{p}$ value $=0.034]$. This could be due for the student, that for awareness campaigns are organized towards high school students in the city of Ouagadougou. For students, this could be due to ten years awareness campaigns organized towards high school students in the city of Ouagadougou.

Adeyemi et al. Ibadan, Nigeria also found themselves a low level of knowledge about hepatitis B in pregnant women, with a significant difference at three different levels of health care [33]. In China, few studies have been published on the subject and provided the basis for the estimation in reproductive age in the general population, women's knowledge level. Chan et al. who investigated the knowledge of HBV infection in a non-randomized cohort of pregnant women attending antenatal clinics in 2008 [34], found themselves insufficient knowledge of HBV infection on various aspects. These results were similar to those of other authors in the world [35]-[39].

In our study, knowledge score increased with level of education. Victoria Nankabirwa et al. infants whose mothers had completed secondary education were two times less likely to miss immunizations planned versus those whose mothers had completed primary education [40]. Child immunization strategies should primarily target women of low educational level. 


\subsection{National Health Policy against Hepatitis B in Pregnant Women}

In Burkina Faso, there is no national prevention of mother to child transmission program (PMTCT) of HBV. In such conditions, the low HBV screening rates among women and the lack of vaccination remedial programs for unimmunized adults may be associated with maintaining a high prevalence of HBV infection in populations [13]. In our study, a minority of women had been vaccinated before prenatal care $(2.26 \%)$ and vaccinations were carried out without informing women about the disease. Health centers accounted secondary information sources $(10.37 \%)$ in contrast to the media $(40.57 \%)$, which were the main source. This is mainly due to two reasons: the disease is little and often poorly understood in general practitioners (lack of information and training) and the majority of health centers offer most of curative services than preventive.

Since 2006, only vaccination against hepatitis B is carried out in the eighth week of life, exposing infants to the risk of contamination during their first two months of life. However, the WHO guidelines for the prevention of HBV recommend vaccination against HBV with a monovalent vaccine within 24 hours of birth, followed by two or three other monovalent or multivalent data in the childhood schedule standard. This strategy provides $95 \%$ of durable protection against chronic HBV infection, with an estimated coverage of at least 20 years and possibly for life [28]. In Africa the effectiveness of vaccination against HBV of infants for the prevention of vertical transmission of HBV was confirmed and estimated at over $80 \%$ in several studies in Africa [41] [42].

We believe that in such a context, vast populations awareness campaigns are urgent to encourage the use of prevention. People should themselves be aware of the danger and go to the screening and vaccination centers. The strategies used by governments could inclurent the implementation of cross-cutting programs of joint fight against HIV and viral hepatitis. It would be a shame not to take advantage of advances made in the fight against HIV. This deficiency was demonstrated in our study, because awareness for hepatitis B had not been systematic in any of the patients who achieved HIV testing in previous prenatal consultations.

We believe these are appropriate times for women's awareness by allowing them to also expose their concerns. According OiKaChan and Andreas A, in countries with limited resources, strategies targeting women of childbearing age for health education would be more profitable because of their role as mothers and their hostess status dealing of the entire household, so improving their knowledge of HBV transmission would have the greatest overall impact on the population [32] [43].

In 2015, the WHO recommendations stipulate that national strategies to prevent perinatal transmission should include in addition to vaccination a combination of enhanced care of the mother and child at birth by skilled health personnel present to administer the vaccine, and awareness/education of mothers on preventive methods. In our study 266 women infected with hepatitis B have been educated to prevent transmission of infection to those around them and their newborns. they were also used as intermediates for the recognition and awareness of their families, a total of 119 spouses who made the screening, 15 (12.6\%) were positive and negative have been directed to immunization.

Regarding the entourage $64.3 \%$ of women not wanting to disclose information on their status, additional studies are needed to assess the weight of stigma in seeking care HBsAg positive women. The proper education of the population could reduce the stigma of HBV carriers; as was the case in the US where higher levels of knowledge regarding HBV have been associated with a decrease stigma [44].

In Burkina Faso, the economic dependence of women with respect to their spouses is an important factor that slows probably seeking care for them. According to the demographic and health surveys in this country, decisions about women's health care is taken, in most cases, by humans. In only $8 \%$ of cases, the woman decides for his own health care [44]. Thus, the education of girls, the improvement of knowledge and the promotion of gainful employment for women are elements that must be taken into account in the assessment of barriers to access to care for women with hepatitis B in our context.

\section{Conclusion}

This study allows us to document the barriers to the adequate prevention of the transmission of hepatitis B in the health district of Baskuy. This collaborative model shows that in a context of insufficient qualified staff and lack of national political support for infected patients, small scale strategies may bear fruit and improve the care of HBsAg-positive women and new borns. We hope that the improvement of the knowledge obtained with health workers will positively impact the management of the district population. This study has allowed us to also find that the improved knowledge of pregnant women on hepatitis B is associated with vaccination of newborns in 
the first 24 hours of life. To improve the fight against hepatitis B in Burkina Faso, it is an imperative for the government to establish a national program against viral hepatitis like in other countries and take advantage of the advances and experience gained in the field of HIV for the benefit of the fight against hepatitis.

\section{Acknowledgements}

We thank all the staff of the health district that made this study possible.

\section{References}

[1] Sombié, R., Bougouma, A., Diallo, O., Bonkoungou, G., Cissé, R., Sangaré, L., Sia, R., Serme, K. and Ilboudo, D. (2010) Chronic Hepatitis B: Epidemiological, Diagnostic, Therapeutic and Evolution at the University Hospital Yalgado Ouédraogo of Ouagadougou. Journal Africain d'Hépato-Gastroentérologie, 4, 3-10. http://dx.doi.org/10.1007/s12157-009-0137-2

[2] Kramvis, A. and Kew, M.C. (2007) Epidemiology of Hepatitis B Virus in Africa, Its Genotypes and Clinical Associations of Genotypes. Hepatology Research, 37, 9-19. http://dx.doi.org/10.1111/j.1872-034X.2007.00098.x

[3] Noreen, I., Flores, Y.N., Ramirez, P., Bastani, R. and Salmerón, J. (2014) Hepatitis and Liver Disease Knowledge and Preventive Practicesamong Health Workers in Mexico: A Cross-Sectional Study. International Journal of Public Health, 59, 381-394. http://dx.doi.org/10.1007/s00038-013-0515-9

[4] Lavanchy, D. (2004) Hepatitis B Virus Epidemiology, Disease Burden, Treatment, and Current and Emerging Prevention and Control Measures. Journal of Viral Hepatitis, 11, 97-107. http://dx.doi.org/10.1046/j.1365-2893.2003.00487.x

[5] Reda, A.A., Fisseha, S., Bezatu, M. and Vandeweerd, J.M. (2010) Standard Precautions: Occupational Exposure and Behavior of Health Care Workers in Ethiopia. PLOS ONE, 12, 1-6. http://dx.doi.org/10.1371/journal.pone.0014420

[6] Kermode, M., Jolley, D., Langkham, B., Thomas, M.S. and Crofts, N. (2005) Occupational Exposure to Blood and Risk of Bloodborne Virus Infection among Health Care Workers in Rural North Indian Health Care Settings. American Journal of Infection Control, 33, 34-41. http://dx.doi.org/10.1016/j.ajic.2004.07.015

[7] Shehab, T.M., Sonnad, S., Gebremariam, A. and Schoenfeld, P. (2002) Knowledge of Hepatitis C Screening and Management by Internal Medicine Residents: Trends over 2 Years. The American Journal of Gastroenterology, 97, 12161222. http://dx.doi.org/10.1111/j.1572-0241.2002.05708.x

[8] Ansa, V.O., Udoma, E.J., Umoh, M.S. and Anah, M.U. (2002) Occupational Risk of Infection by Human Immunodeficiency and Hepatitis B Viruses among Health Workers in South-Eastern Nigeria. East African Medical Journal, 79, 254-256. http://dx.doi.org/10.4314/eamj.v79i5.8863

[9] Zafar, A., Aslam, N., Nasir, N., Meraj, R. and Mehraj, V. (2008) Knowledge, Attitudes, and Practices of Health Care Workers Regarding Needle Stick Injuries at a Tertiary Care Hospital in Pakistan. Journal of Pakistan Medical Association, 58, 57-60.

[10] Pietra, V., Kiema, D. and Sorgho, D. (2008) Prevalence of Markers of Hepatitis B and Antibodies against the Hepatitis C among the Staff of the Health District Nanoro, Burkina Faso. Sciences et Techniques, Sciences de la Santé, 2, 53-59.

[11] Hoz, F.D.L., Perez, L., Wheeler, J.G., de Neira, M. and Hall, A.J. (2005) Vaccine Coverage with Hepatitis B and Other Vaccines in the Colombian Amazon: Do Health Worker Knowledge and Perception Influence Coverage? Tropical Medicine \& International Health, 10, 322-329. http://dx.doi.org/10.1111/j.1365-3156.2005.01399.x

[12] Tao, I., Compaoré, T.R., Diarra, B., Djigma, F., Zohoncon, T.M., Assih, M., Ouermi, D., Pietra, V., Karou, S.D. and Simpore, J. (2014) Séroépidémiologie du virus de l’hépatite B et C dans la population générale du Burkina Faso. Hepatitis Research and Treatment, 1, 1-5. http://dx.doi.org/10.1155/2014/781843

[13] Sangaré, L., Sombié, R., Combasséré, A.W., Kouanda, A., Kania, D., Zerbo, O. and Lankoandé, J. (2009) Antenatal Transmission of Hepatitis B Prevalence in Moderate Area of HIV, Ouagadougou, Burkina Faso. Bulletin de la Société de Pathologie Exotique, 102, 226-229.

[14] Dao, B., Nacro, B., Dahourou, H., Meda, N. and Deperre, P.V. (2001) Co-Infection of Hepatitis B and HIV: Prevalence Survey among Pregnant Women in Bobo Dioulasso, Burkina Faso. Revue Médicale de Bruxelles, 22,83-86.

[15] Collenberg, E., Ouedraogo, T., Ganamé, J., Fickenscher, H., Kynast-Wolf, G., Becher, H., Kouyaté, B., Kräusslich, H.G., Sangaré, L. and Tebit, D.M. (2006) Seroprevalence of Six Different Viruses among Pregnant Women and Blood Donors in Rural and Urban Burkina Faso: A Comparative Analysis. Journal of Medical Virology, 78, 683-692. http://dx.doi.org/10.1002/jmv.20593

[16] Simpore, J., Granato, M., Santarelli, R., Nsme, R.A., Coluzzi, M., Pietra, V., Pignatelli, S., Bere, A., Faggioni, A. and Angeloni, A. (2004) Prevalence of Infection by HHV-8, HIV, HCV and HBV among Pregnant Women in Burkina Faso. Journal of Clinical Oncology, 31, 78-80. http://dx.doi.org/10.1016/j.jcv.2004.06.001 
[17] Simpore, J., Savadogo, A., Ilboudo, D., Nadambega, M.C., Esposito, M., Yara, J., Pignatelli, S., Pietra, V. and Musumeci, S. (2006) Toxoplasma Gondii, HCV and HBV Seroprevalence and Co-Infection among HIV Positive and Negative Pregnant Women in Burkina Faso. Journal of Medical Virology, 78, 730-733. http://dx.doi.org/10.1002/jmv.20615

[18] Ilboudo, D., Sawadogo, A. and et Simporé, J. (2002) Mother-to-Child Transmission of the Virus of Hepatitis B in Ouagadougou, Burkina Faso. Medecine Tropicale, 62, 99-101.

[19] Xu, D.Z., Yan, Y.P., Choi, B.C., Xu, J.Q. and Men, K. (2002) Risk Factors and Mechanism of Transplacental Transmission of Hepatitis B Virus: A Case-Control Study. Journal of Medical Virology, 67, 20-26. http://dx.doi.org/10.1002/jmv.2187

[20] Zhang, S.L., Yue, Y.F., Bai, G.Q., SHI, L. and Jiang, H. (2004) Mechanism of Intrauterine Infection of Hepatitis B Virus. World Journal of Gastroenterology, 10, 437-438.

[21] Ranger-Rogez, S. and et Denis, F. (2004) Hepatitis B Mother-to-Child Transmission. Expert Review of Anti-Infective Therapy, 2, 133-145. http://dx.doi.org/10.1586/14787210.2.1.133

[22] Hou, J., Liu, Z. and Gu, F. (2005) Epidemiology and Prevention of Hepatitis B Virus Infection. International Journal of Medical Sciences, 2, 50-57. http://dx.doi.org/10.7150/ijms.2.50

[23] Alter, M.J. and Margolis, H.S. (1990) The Emergence of Hepatitis B as a Sexually Transmitted Disease. Medical Clinics of North America, 74, 1529-1541. http://dx.doi.org/10.1016/S0025-7125(16)30493-X

[24] Simonsen, L., Kane, A., Lloyd, J., Zaffran, M. and Kane, M. (1999) Unsafe Injections in the Developing World and Transmission of Bloodborne Pathogens: A Review. Bulletin of the World Health Organization, 77, 789-800.

[25] Kane, A., Lloyd, J., Zaffran, M., Simonsen, L. and Kane, M. (1999) Transmission of Hepatitis B, Hepatitis C and Human Immunodeficiency Viruses through Unsafe Injections in the Developing World: Model-Based Regional Estimates. Bulletin of the World Health Organization, 77, 801-807.

[26] Dongdem, J.T., Kampo, S., Soyiri, I.N., Asebga, P.N., Ziem, J.B. and Sagoe, K. (2012) Prevalence of Hepatitis B Virus Infection among Blood Donors at the Tamale Teaching Hospital, Ghana (2009). BMC Research Notes, 5, 115. http://dx.doi.org/10.1186/1756-0500-5-115

[27] Lavanchy, D. (2004) Hepatitis B Virus Epidemiology, Disease Burden, Treatment, and Current and Emerging Prevention and Control Measures. Journal of Viral Hepatitis, 11, 97-107. http://dx.doi.org/10.1046/j.1365-2893.2003.00487.x

[28] Howell, J., Lemoine, M. and Thursz, M. (2014) Prevention of Materno-Foetal Transmission of Hepatitis B in Sub-Saharan Africa: The Evidence, Current Practice and Future Challenges. Journal of Viral Hepatitis, 21, 381-396. http://dx.doi.org/10.1111/jvh.12263

[29] Kwan, L.C., Ho, Y.Y. and Lee, S.S. (1997) The Declining HBsAg Carriage Rate in Pregnant Women in Hong Kong. Epidemiology \& Infection, 119, 281-283. http://dx.doi.org/10.1017/S0950268897007796

[30] Chan, C.Y., Lee, S.D. and Lo, K.J. (2004) Legend of Hepatitis B Vaccination: The Taiwan Experience. Journal of Gastroenterology and Hepatology, 19, 121-126. http://dx.doi.org/10.1111/j.1440-1746.2004.03153.X

[31] Chang, M.H., Chen, C.J., Lai, M.S., Hsu, H.M., Wu, T.C., Kong, M.S., Liang, D.C., Shau, W.Y. and Chen, D.S. (1997) Universal Hepatitis B Vaccination in Taiwan and the Incidence of Hepatocellular Carcinoma in Children. The New England Journal of Medicine, 336, 1855-1859. http://dx.doi.org/10.1056/NEJM199706263362602

[32] Chan, O.K., Terence, T.L., Suen, S.H. and TakYeung, L. (2012) Deficient Knowledge on Hepatitis B Infection in Pregnant Women and Prevalence of Hepatitis B Surface Antigen Carriage in an Endemic Area: A Review. Hepatitis Research and Treatment, 2012, Article ID: 317451. http://dx.doi.org/10.1155/2012/317451

[33] Adeyemi, A.B., Enabor, O.O., Ugwu, I.A., Bello, F.A. and Olayemi, O.O. (2013) Knowledge of Hepatitis B Virus Infection, Access to Screening and Vaccination among Pregnant Women in Ibadan, Nigeria. Journal of Obstetrics and Gynaecology, 33, 155-159. http://dx.doi.org/10.3109/01443615.2012.711389

[34] Chan, O.K., Lao, T.T., Suen, S.S.H., Lau, T.K. and Leung, T.Y. (2010) Knowledge on Hepatitis B Infection among Pregnant Women in a High Endemicity Area. Patient Education and Counseling, 85, 516-520. http://dx.doi.org/10.1016/j.pec.2010.11.006

[35] Thompson, M.J., Taylor, V.M., Yasui, Y., Hislop, T.G., Jackson, J.C., Kuniyuki, A. (2003) Hepatitis B Knowledge and Practices among Chinese Canadian Women in Vancouver, British Columbia. Canadian Journal of Public Health, 94, 281-286.

[36] Taylor, V.M., Tu, S.P., Woodall, E., Acorda, E., Chen, H. and Choe, J. (2006) Hepatitis B Knowledge and Practices among Chinese Immigrants to the United States. Asian Pacific Journal of Cancer Prevention, 7, 313-317.

[37] Hislop, T.G., Teh, C., Low, A., Lin, L., Shin-Ping, T., Yutaka, Y. and Lin, L. (2007) Hepatitis B Knowledge, Testing 
and Vaccination Levels in Chinese Immigrants to British Columbia, Canada. Canadian Journal of Public Health, 98, 125-129.

[38] Ma, G.X., Shive, S.E., Toubbeh, J.I., Tan, Y., and Wu, D. (2008) Knowledge, Attitudes, and Behaviors of Chinese Hepatitis B Screening and Vaccination. American Journal of Health Behavior, 32, 178-187. http://dx.doi.org/10.5993/AJHB.32.2.7

[39] Cotler, S.J., Cotler, S., Xie, H., Luc, B.J., Layden, T.J. and Wong, S.S. (2012) Characterizing Hepatitis B Stigma in Chinese Immigrants. Journal of Viral Hepatitis, 19, 147-152. http://dx.doi.org/10.1111/j.1365-2893.2011.01462.x

[40] Nankabirwa, V., Tylleskär, T., Tumwine, J.K. and Sommerfelt, H. (2010) Maternal Education Is Associated with Vaccination Status of Infants Less than 6 Months in Eastern Uganda: A Cohort Study. BMC Pediatrics, 10, 92. http://dx.doi.org/10.1186/1471-2431-10-92

[41] Montesano, R. (2002) Hepatitis B Immunization and Hepatocellular Carcinoma: The Gambia Hepatitis Intervention Study. Journal of Medical Virology, 67, 444-446. http://dx.doi.org/10.1002/jmv.10093

[42] Mendy, M., D’Mello, F., Kanellos, T., Oliver, S., Whittle, H. and Howard, C.R. (2008) Envelope Protein Variability among HBV-Infected Asymptomatic Carriers and Immunized Children with Breakthrough Infections. Journal of Medical Virology, 80, 1537-1546. http://dx.doi.org/10.1002/jmv.21221

[43] Andreas, A., Frambo, B., Atashili, J., Nde, P.F. and Ndumbe, P.M. (2014) Prevalence of HBsAg and Knowledge about Hepatitis B in Pregnancy in the Buea Health District, Cameroon: A Cross-Sectional Study. BMC Research Notes, 7, 394. http://dx.doi.org/10.1186/1756-0500-7-394

[44] Cotler, S.J., Cotler, S., Xie, H., Luc, B.J., Layden, T.J., Wong, S.S. (2012) Characterizing Hepatitis B Stigma in Chinese Immigrants. Journal of Viral Hepatitis, 19, 147-152. http://dx.doi.org/10.1111/j.1365-2893.2011.01462.x 